\title{
Onsite production of medical air: is purity a problem?
}

\author{
Paul Edwards ${ }^{1}$, Patricia-Ann Therriault ${ }^{1}$ and Ira Katz ${ }^{2,3^{*}}$ (D)
}

\begin{abstract}
Introduction: Medical air (MA) is widely used in hospitals, often manufactured onsite by compressing external ambient air and supplied through a local network piping system. Onsite production gives rise to a risk of impurities that are governed by the same pharmacopoeia purity standards applicable to commercially produced MA. The question to be addressed in this paper is how to assess if a lack of purity poses a medical problem?

Methods: The MA produced onsite at a major Canadian hospital was monitored for carbon dioxide $\left(\mathrm{CO}_{2}\right)$ and other impurity gases at high frequency (one per minute) over a two-month period.

Results: The average $\mathrm{CO}_{2}$ concentration was 255 ppm. The United States Pharmacopeia (USP) threshold of $500 \mathrm{ppm}$ was exceeded during $1 \%$ of the total study period, and the average while exceeding the threshold was 526 ppm. The maximum concentration was 634 ppm.

Discussion and conclusion: To our knowledge, there is only one study that evaluated the effects suffered by respiratory patients of elevated nitric oxide in MA; thus, it is not clear what are the medical bases for the thresholds stated in the USP. To perform a Quality Risk Assessment, the threshold and the time above threshold should be considered in determining the frequency of sampling and analysis, and operating methods required to ensure the quality of MA entering the pipeline meets the clinical, regulatory, and patient safety standards. In conclusion, because the USP does not provide impurity thresholds for specific patients nor time above thresholds, there is a need for the medical community to determine these quantities before it can be known if the purity of MA is a problem.
\end{abstract}

Keywords: Medical air, Risk assessment, Carbon dioxide

\section{Introduction}

Medical air (MA) is widely used for aerosol drug delivery, high flow therapy, mechanical ventilation, neonatal environment control, infant resuscitation, general anesthesia, and hyperbaric therapy. MA can be produced by external manufacturers, filled in cylinders and transported to the site of use. This form of supply is directly regulated by the relevant country's pharmacopeia [1]. However, for hospitals MA is most efficiently manufactured onsite by compressing external ambient air and supplied through a local network piping system. Onsite production gives rise to a risk of impurities that are governed by the same pharmacopoeia purity standards, and should be assessed

\footnotetext{
*Correspondence: ira.katz@airliquide.com

${ }^{2}$ Medcial R\&D, Air Liquide Santé International, 78354 Les Loges-en-Josas, France

${ }^{3}$ Department of Mechanical Engineering, Lafayette College, Easton, PA 18042, USA

Full list of author information is available at the end of the article
}

by the facility's staff [2]. The sources of impurities can be categorized as systemic or extrinsic; where the systemic sources arise due to the manufacturing and distribution systems themselves and extrinsic sources arise from the external air input. Furthermore, the extrinsic sources are either endemic (i.e., local to the production site) or ambient (arising from the pollution levels in the environment).

In brief, onsite MA production consists of outside air being drawn into the system by a compressor, through particulate filters. The MA passes through a dryer before entering the distribution network. There also must be a backup supply based on cylinders. Note that there would usually be multiple components such as compressors and dryers to optimize production and to account for normal downtime. Of particular importance are dryers that consist of dual columns that operate on the principle of pressure swing adsorption, when one column swings to

(c) The Author(s). 2018 Open Access This article is distributed under the terms of the Creative Commons Attribution 4.0 International License (http://creativecommons.org/licenses/by/4.0/), which permits unrestricted use, distribution, and reproduction in any medium, provided you give appropriate credit to the original author(s) and the source, provide a link to the Creative Commons license, and indicate if changes were made. The Creative Commons Public Domain Dedication waiver (http://creativecommons.org/publicdomain/zero/1.0/) applies to the data made available in this article, unless otherwise stated. 
low pressure to dehumidify the absorbing material and the second takes over as the active dryer.

For context, the United States Pharmacopeia (USP) threshold values for MA are: oxygen $<19.5 \% \mathrm{v} / \mathrm{v}$ and $>23$. $5 \% \mathrm{v} / \mathrm{v}$, carbon monoxide $>10 \mathrm{ppm}$, carbon dioxide > $500 \mathrm{ppm}$, nitrous oxide + nitric oxide $>2.5 \mathrm{ppm}$, sulphur dioxide $>5 \mathrm{ppm}$, and humidity $<-5{ }^{\circ} \mathrm{C}$ pressure dew point [3].

The question to be addressed in this paper is how to assess the purity of onsite produced MA and if a lack of purity poses a medical problem. That is, what are the elements of a Quality Risk Assessment for onsite produced MA that should be understood and addressed by the medical community. We take advantage of a unique sample dataset; high frequency measurements (one per minute) over a two-month period of carbon dioxide $\left(\mathrm{CO}_{2}\right)$ to frame the discussion.

\section{Methods}

The MA produced onsite at a major Canadian hospital (the name of the hospital cannot be revealed for contractual reasons) was monitored using an AerAlin device (Vitalaire, Mississauga, Canada) that monitors the oxygen content and contaminant levels. Using seven independent sensors the AerAlin can monitor the following USP designated components: oxygen, carbon dioxide, carbon monoxide (CO), dewpoint (to determine humidity), nitric oxide and nitrogen dioxide together (NOx), and sulphur dioxide $\left(\mathrm{SO}_{2}\right)$. In this short paper we only report in detail on $\mathrm{CO}_{2}$ results. The internal $\mathrm{CO}_{2}$ sensor (Vaisala CARBOCAP series GMT220, Helsinki, Finland) has an accuracy: \pm (1.5\% of range $+2 \%$ of reading). This sensor has been used in a wide variety of scientific and industrial activities [4-6]. Measurements were recorded at a frequency of $1 / \mathrm{min}$, from July 28th to September 12th, 2017.

\section{Results}

Figure 1 shows the time history of $\mathrm{CO}_{2}$ concentration during the study period. The red horizontal line is the USP threshold. The average $\mathrm{CO}_{2}$ concentration was $255 \mathrm{ppm}$. The USP threshold of $500 \mathrm{ppm}$ was exceeded during $1 \%$ of the total study period (719 measurements), and the average while exceeding the threshold was $526 \mathrm{ppm}$. The maximum concentration was $634 \mathrm{ppm}$.

Considering the other USP criteria; there were nine threshold breaches of NOx (maximum $2.7 \mathrm{ppm}$ ) with an overall average of $0.03 \mathrm{ppm}$. There were no threshold breaches for the other USP criteria: $\mathrm{O}_{2}$ (avg 21.0\%, max 21.1\%, min 20.9\%), CO (avg $1.7 \mathrm{ppm}$, $\max 9.6 \mathrm{ppm}$ ), dew point (avg $-42.1{ }^{\circ} \mathrm{C}$, max $8.3^{\circ} \mathrm{C}$ ), and $\mathrm{SO}_{2}$ (avg $<0$. $001 \mathrm{ppm}$, max $0.1 \mathrm{ppm}$ ).

\section{Discussion and conclusion}

In this paper a dataset of $\mathrm{CO}_{2}$ concentration measurements in onsite produced MA indicates periodic breaches in the USP threshold. To our knowledge, this is the first example of testing of onsite production of MA to appear in the peer reviewed literature.

The reason for the breaches in $\mathrm{CO}_{2}$ threshold are attributed by us to the dryer, which captures $\mathrm{CO}_{2}$ concomitant to humidity. When it is almost saturated with humidity, before the swing to purge mode, previously captured $\mathrm{CO}_{2}$ is released into the airstream at higher concentrations than in the original supply. Thus, this is considered a systematic impurity source.

We believe this example of $\mathrm{CO}_{2}$ concentration presented herein showing periodic systematic impurity breaches is representative of potential extrinsic impurity problems, though during the measurement period at this site there were only the nine other threshold breaches of NOx (maximum 2.7 ppm).

While there are numerous studies confirming the health effects of common air pollutants [7], to our knowledge

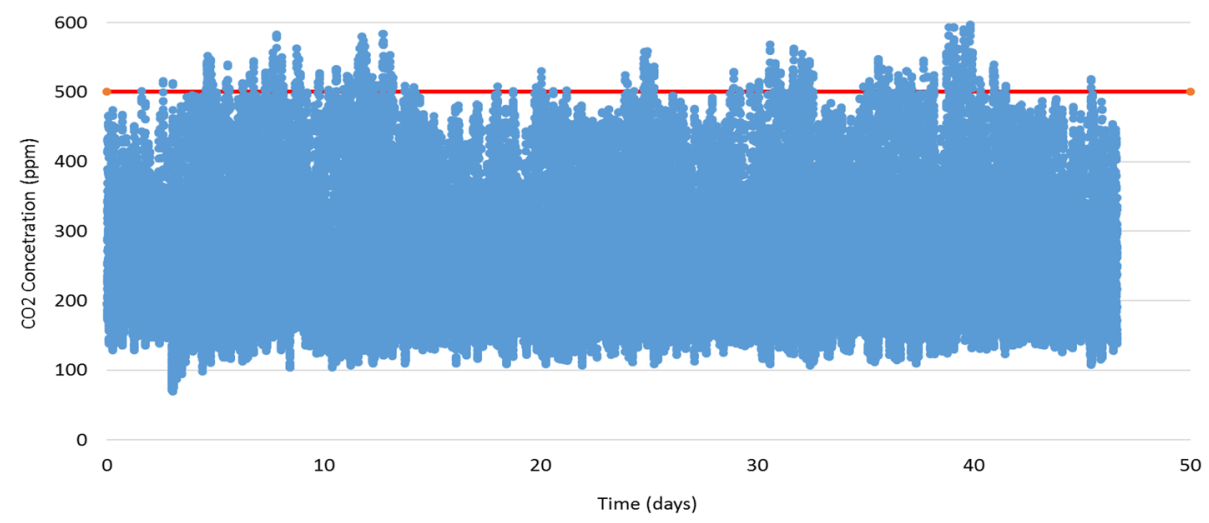

Fig. 1 The time history of $\mathrm{CO}_{2}$ concentration. The USP threshold of $500 \mathrm{ppm}$ is shown in red 
there is only one study that evaluated the effects suffered by respiratory patients inhaling contaminated MA. This study showed that unintended inhalation of $\mathrm{NO}$ in industrialized areas may alter the $\mathrm{PaO}_{2}$ and may make the therapeutic use of NO less successful [8]. Another study concluded that low levels of carboxyhemoglobin (due to breathing $\mathrm{CO}$ ) exacerbate myocardial ischemia during graded exercise in subjects with coronary artery disease [9]. Thus, overall it is not clear what are the medical bases for the thresholds stated in the USP.

To perform a Quality Risk Assessment, the threshold and the time above threshold should be considered in determining the frequency of sampling and analysis, and operating methods required to ensure the quality of MA entering the pipeline meets the clinical, regulatory, and patient safety standards. In the greater context of MA provided in cylinders, recalls have been made for levels of 720 PPM [10].

In conclusion, because the USP does not provide impurity thresholds for specific patients nor time above thresholds, there is a need for the medical community to determine these quantities before it can be known if the purity of MA is a problem.

Availability of data and materials

Upon request

\section{Authors' contributions}

PE and P-AT designed the data acquisition and read the manuscript, IK analyzed the data and drafted the manuscript. All authors read and approved the final manuscript.

Ethics approval and consent to participate

Not applicable

\section{Competing interests}

Vitalaire, Canada is a provider of medical air systems and monitoring services. PE and PAT works in Vitalaire-Canada, whereas IK is part of Medical R\&D of Air Liquide Santé International.

\section{Publisher's Note}

Springer Nature remains neutral with regard to jurisdictional claims in published maps and institutional affiliations.

\section{Author details}

${ }^{1}$ VitalAire Canada Inc., Mississauga, ON L5N 8R9, Canada. ${ }^{2}$ Medcial R\&D, Air Liquide Santé International, 78354 Les Loges-en-Josas, France. ${ }^{3}$ Department of Mechanical Engineering, Lafayette College, Easton, PA 18042, USA.

Received: 12 March 2018 Accepted: 5 April 2018

Published online: 07 May 2018

\section{References}

1. Government of Canada CC for OH and S. CAN/CSA-Z7396-1-2009 - Medical gas pipeline systems - Part 1: pipelines for medical gases and vacuum. 2009 [cited 2018 Apr 10]. Available from: https://www.lokring.com/wp-content/ uploads/Approvals/CSA-Z7396-1-2009.pdf.

2. Pinsky MR, Genc F, Lee KH, Delgado E. Contamination of hospital compressed air with nitric oxide: unwitting replacement therapy. Chest. 1997;111:1759-63. [cited 2018 Feb 27]. Available from: http://journal. chestnet.org/article/S0012-3692(15)47074-6/abstract

3. USP Monographs: Medical air. [cited 2018 Feb 27]. Available from: http:// www.pharmacopeia.cn/v29240/usp29nf24s0_m1000.html
4. De Godos I, Mendoza JL, Acién FG, Molina E, Banks CJ, Heaven S, et al. Evaluation of carbon dioxide mass transfer in raceway reactors for microalgae culture using flue gases. Bioresour Technol. 2014;153:307-14.

5. Messerli J, Bertrand A, Bourassa J, Bélanger G, Castonguay $Y$, Tremblay G, et al. Performance of low-cost open-top chambers to study long-term effects of carbon dioxide and climate under field conditions. Agron J. 2015;107:916-20.

6. Tsalaporta E, Brady N, MacElroy JMD. Experimental and modelling studies of CO2/N2 mixture separations using amine functionalised silicas. Adsorption. 2017;23:847-69.

7. $\mathrm{WHO} \mid$ Air quality guidelines - global update 2005 [Internet]. WHO. [cited 2018 Feb 27]. Available from: http://www.who.int/phe/health_topics/ outdoorair/outdoorair_aqg/en/

8. Benzing A, Loop T, Mols G, Geiger K. Unintended inhalation of nitric oxide by contamination of compressed air physiologic effects and interference with intended nitric oxide inhalation in acute lung injury. Anesthesiol J Am Soc Anesthesiol. 1999;91:945. [cited 2018 Feb 27]. Available from: http:// anesthesiology.pubs.asahq.org/article.aspx?articleid=1945903

9. Allred EN, Bleecker ER, Chaitman BR, Dahms TE, Gottlieb SO, Hackney JD, et al. Short-term effects of carbon monoxide exposure on the exercise performance of subjects with coronary artery disease. N Engl J Med. 1989; 321:1426-32. Available from: https://doi.org/10.1056/NEJM198911233212102

10. Air USP [Internet]. [cited 2018 Feb 28]. Available from: http://healthycanadians. gc.ca/recall-alert-rappel-avis/hc-sc/2013/26859r-eng.php

\section{Ready to submit your research? Choose BMC and benefit from:}

- fast, convenient online submission

- thorough peer review by experienced researchers in your field

- rapid publication on acceptance

- support for research data, including large and complex data types

- gold Open Access which fosters wider collaboration and increased citations

- maximum visibility for your research: over $100 \mathrm{M}$ website views per year

At BMC, research is always in progress.

Learn more biomedcentral.com/submissions 